\title{
New mutualistic fungal endophytes isolated from poplar roots display high metal tolerance
}

\author{
Laurence Lacercat-Didier ${ }^{1}$ \& Charlotte Berthelot ${ }^{1} \&$ Julie Foulon ${ }^{3}$ \& Audrey Errard ${ }^{1}$ \& Elena Martino ${ }^{2}$ \& Michel \\ Chalot $^{3,4}$ \& Damien Blaudez ${ }^{1}$ \\ ${ }^{1}$ Laboratoire Interdisciplinaire des Environnements Continentaux, UMR 7360 CNRS/Université de Lorraine, Faculté des Sciences et \\ Technologies, BP 70239, F-54506 Vandoeuvre-les-Nancy, France \\ ${ }^{2}$ Department of Life Sciences and Systems Biology, University of Torino, Viale Mattioli 25, 10125 Turin, Italy \\ ${ }^{3}$ Laboratoire Chrono-Environnement, UMR 6249 CNRS/Université de Bourgogne Franche-Comté, Pôle Universitaire du Pays de \\ Montbéliard, 4 place Tharradin, BP 71427, F-25211 Montbéliard, France \\ ${ }_{4}^{4}$ Faculté des Sciences et Technologies, Université de Lorraine, BP 70239, F-54506 Vandoeuvre-les-Nancy, France
}

\begin{abstract}
This study aimed to isolate, identify, and character- ise metal-tolerant fungi colonising poplar roots at a metal- contaminated phytoremediation site. Poplar roots were colonised by arbuscular mycorrhizal, ectomycorrhizal, and endophytic fungi, and the species were determined by ITS molecular analyses. Eight different isolates were successfully isolated into pure culture. Three isolates belonging to the Helotiales (P02, P06) and the Serendipita vermifera species (P04) were highly tolerant to metals ( $\mathrm{Cd}, \mathrm{Zn}, \mathrm{Pb}$, and $\mathrm{Cu}$ ) compared to the mycorrhizal Hebeloma isolates. The three isolates degraded complex carbohydrates, such as xylan and cellulose, indicating that they could partially degrade root cell walls and penetrate into cells. This hypothesis was confirmed by further in vitro re-synthesis experiments, which showed that the three isolates colonised root tissues of poplar plantlets whereas two of them formed microsclerotia-like structures. Taken together, these results suggest an endophytic lifestyle of these isolates. This is the first evidence of S. vermifera as a root endophyte of poplar. A new endophytic putative species belonging to the Helotiales and closely related to Leohumicola is also reported. Interestingly, and when compared to mockinoculated plants, both P06 and P04 isolates increased the number of root tips of inoculated poplar plantlets in vitro. Moreover, the S. vermifera P04 isolate also increased the shoot biomass. The results are discussed in relation to the potential use of endophytic strains for tree-based phytoremediation of metalcontaminated sites.
\end{abstract}

Keywords: Helotiales · Mycorrhizal fungi · Endophytic fungi · Poplar · Metals · Serendipita vermifera

\section{Introduction}

Poplars (Salicaceae) are widely distributed in the northern hemisphere in different habitats and comprise approximately 30 species (Hamzeh and Dayanandan 2004). Populus is now increasingly utilised for reforestation of post-agricultural land, recultivation of areas degraded by industry or environmental pollution, and as a renewable source of biomass for bioenergy production (Capuana 2011). Poplars are ideal candidates for use in phytoremediation of metal-contaminated sites, as they meet several requirements: high biomass production usable for renewable energy production, fast growth, a deep and widespread root system, and excellent metal tolerance and accumulation capacities (Migeon et al. 2009; Capuana 2011; Migeon et al. 2012). Moreover, poplar is a model species for molecular studies of woody plants (Tuskan et al. 2006). Researchers have mainly focused their studies on the above- ground parts of poplar trees, analysing their responses to en- vironmental factors (Migeon et al. 2009; Capuana 2011; Migeon et al. 2012).

Tree roots are naturally associated to various soil microor- ganisms, and these associations are crucial because they can directly or indirectly affect the mobility, bioavailability, and accumulation of elements by host plants. As for most trees in temperate and boreal forests, the establishment, growth, and survival of poplar trees in the wild and in large plantations depend strongly on colonisation by mycorrhizal fungi (Smith and Read 2008). Mycorrhizal fungi are therefore im- portant for the recovery of polluted sites via phytoremediation, as they play crucial roles in soil fertility, plant nutrition, and colonisation and they can both enhance plant mineral uptake and restrict metal accumulation in plants (Likar 2011; Singh et al. 2011; Meier et al. 2012). Poplars are among the few culti- vated trees in the temperate climate zone that together 
with willows and alders form tripartite symbiotic associations with ectomycorrhizal (ECM) and arbuscular mycorrhizal (AM) fungi (Khasa et al. 2002; Gehring et al. 2006). Endophytic fungi can also influence the distribution, ecology, and biology of plants (Rodriguez et al. 2009). Endophytic fungi form pu- tative symbiotic interactions with plants and live within plant tissues without producing noticeable symptoms (Rodriguez et al. 2009). Unlike mycorrhizal fungi that colonise plant roots and grow into the rhizosphere, fungal endophytes reside en- tirely within plant tissues. Dark septate endophytes (DSE) are fungi colonising plant roots and are distinguished as a func- tional group based on the presence of darkly melanised interand intracellular septate hyphae and microsclerotia (Rodriguez et al. 2009). Recent studies reported a high diver- sity of DSE associated with the roots of willows or poplars and suggested that root colonisation by these fungi was not affect- ed in highly metal-contaminated locations (Likar and Regvar 2009; Karliński et al. 2010; Regvar et al. 2010). These authors therefore suggested that DSE could improve metal tolerance of trees in highly contaminated areas.

The results obtained regarding tree interactions with those beneficial soil microorganisms could open up perspectives for their use in phytoremediation. Fungi isolated from contami- nated soils develop adaptative mechanisms to tolerate metals (Colpaert et al., 2000; Colpaert et al., 2004; Gonçalves et al. 2009; Jourand et al. 2010; Colpaert et al. 2011). Some authors suggested that mycorrhizal fungi isolated from metal-polluted sites presented a higher tolerance to metals than fungi isolated from non-polluted sites (Gonçalves et al. 2009; Jourand et al. 2010; Colpaert et al. 2011). Moreover, plants inoculated with metal-tolerant mycorrhizal (Adriaensen et al. 2005; Redon et al. 2009; Colpaert et al. 2011) or endophytic (Shahabivand et al. 2012; Likar and Regvar 2013) fungi showed enhanced tolerance when compared to plants inocu- lated with non-tolerant fungi.

The present work was part of a large-scale project whose objective was to study the impact of genotypic variability on phytoremediation capacities of poplar (very) short-rotation coppice (SRC). As a first step toward tree-based phytoremediation assisted by symbiotic fungi, our objectives were: (1) to identify the main symbiotic fungi associated with poplar roots collected from a contaminated site, (2) to isolate metaltolerant fungal endophytes, and (3) to provide some initial characterisation of the most metal-tolerant isolates.

\section{Materials and methods}

\section{Description of the phytoremediation site and sampling}

The experimental site was located northwest of Paris in Pierrelaye (latitude: $49^{\circ} 029$ north; longitude: $2^{\circ} 176$ east). The raw wastewaters from Paris have been used for more than 100 years for the irrigation of the Pierrelaye-Bessancourt plain, which was used for market gardening. As a result of these inputs, this area of more than 1200 ha has been strongly enriched in metals in the surface horizons compared to the natural pedogeochemical background values and to the usual local agricultural contents (Table 1). $\mathrm{Zn}, \mathrm{Cd}, \mathrm{Pb}$, and $\mathrm{Cu}$ are the major pollutants, and the site is also slightly contaminated by $\mathrm{Co}, \mathrm{Cr}$, and $\mathrm{Ni}$. Other soil characteristics are reported in Table 1. Crop production for human consumption was prohibited in the late 1990s (Lamy et al. 2006) and had to be replaced by alternative uses (e.g. production of non- accumulating cereals for animals, culture of miscanthus or woody species for fibre or energy production) providing other types of ecosystem services.

Within the Phytopop project (ANR PRECODD), a 3-ha field demonstration trial was implemented in 2007, with pop- lars grown as SRC for bioenergy production. Our major goal was to select the most efficient poplar hybrids for high bio- mass production in this contaminated zone. For the present study, the two most promising poplar hybrids (Chalot et al., unpublished data) were selected, namely P. trichocarpa x P. maximowiczii and P. deltoides x P. nigra. Fine roots (5-20 cm depth) of both poplar hybrids were collected in autumn from ten trees ( 3 years old) from four different areas of $400 \mathrm{~m}^{2}$, giving a total of 40 samples per hybrid. The roots were traced to their origin to ensure that they were indeed connected to the selected tree and were sampled at a distance of $1 \mathrm{~m}$ from the trunk. 
Table 1 Metal contents and soil characteristics at the phytoremediation site of Pierrelaye

\begin{tabular}{|c|c|c|c|c|}
\hline & Units & $\begin{array}{l}\text { Phytoremediation } \\
\text { site }\end{array}$ & NPBV & UAC \\
\hline Cd total & $\mathrm{mg} / \mathrm{kg}$ & $2.2-4.0$ & $\begin{array}{r}0.02- \\
0.14\end{array}$ & $\begin{array}{r}0.2- \\
0.4\end{array}$ \\
\hline Co total & $\mathrm{mg} /$ & $5.4-13$ & $2-4$ & $3-8$ \\
\hline Cr total & $\mathrm{mg} /$ & $43-89$ & $14-21$ & $15-29$ \\
\hline Cu total & $\mathrm{mg} / \mathrm{kg}$ & $99-230$ & $2-6$ & $8-19$ \\
\hline $\mathrm{Pb}$ total & $\mathrm{mg} / \mathrm{kg}$ & $184-254$ & $4-8$ & $18-43$ \\
\hline Ni total & $\mathrm{mg} / \mathrm{kg}$ & $19-42$ & $4-8$ & $6-20$ \\
\hline $\mathrm{Zn}$ total & $\mathrm{mg} / \mathrm{kg}$ & $394-712$ & $9-19$ & $34-63$ \\
\hline $\begin{array}{l}\mathrm{Cd}\left(\mathrm{NH}_{4} \mathrm{NO}_{3}-\right. \\
\text { extracted) }\end{array}$ & $\mu \mathrm{g} / \mathrm{kg}$ & $21-29$ & nd & nd \\
\hline $\begin{array}{l}\mathrm{Cu}\left(\mathrm{NH}_{4} \mathrm{NO}_{3}-\right. \\
\text { extracted) }\end{array}$ & $\mu \mathrm{g} / \mathrm{kg}$ & $530-812$ & nd & nd \\
\hline $\mathrm{Pb}\left(\mathrm{NH}_{4} \mathrm{NO}_{3}\right.$-extracted $)$ & $\mu \mathrm{g} / \mathrm{kg}$ & $14-29$ & nd & nd \\
\hline $\begin{array}{l}\mathrm{Zn}\left(\mathrm{NH}_{4} \mathrm{NO}_{3-}-\right. \\
\text { extracted })\end{array}$ & $\mu \mathrm{g} / \mathrm{kg}$ & $1400-2010$ & nd & nd \\
\hline $\mathrm{pH}$ & - & $6.8-7.4$ & nd & $\begin{array}{r}7.7- \\
8.2\end{array}$ \\
\hline $\mathrm{C}$ total & $\mathrm{g} / \mathrm{kg}$ & $28-66$ & nd & $10-11$ \\
\hline $\mathrm{N}$ total & $\mathrm{g} / \mathrm{kg}$ & $1.6-2.7$ & nd & nd \\
\hline $\mathrm{P}_{2} \mathrm{O}_{5}$ (Olsen) & $\mathrm{g} / \mathrm{kg}$ & $2.4-5.1$ & nd & nd \\
\hline
\end{tabular}

$N P B V$ natural pedogeochemical background values from five deep horizons (from Lamy et al. 2006), UAC usual agricultural contents in surface horizons in the non-irrigated surrounding area (from Lamy et al. 2006), $n d$ not determined

\section{Evaluation of root colonisation by fungi}

To evaluate the rate of root colonisation by ECM fungi, the entire root portions were first carefully washed with distilled water, and 300 randomly selected root tips per sample were subsequently examined and assessed as ECM or non- mycorrhizal under a stereomicroscope $(\times 10$ magnification). To evaluate the rate of root colonisation by AM fungi and DSE, the fungal structures within the roots were stained with methyl blue and observed under a microscope, as previously described (Trouvelot et al. 1986). Overall, 75 root fragments were observed per sample. The intensity of cortex colonisa- tion by AM fungi (\%AM) and the arbuscular density (\%A) were calculated, as previously described (Trouvelot et al. 1986). Similarly, the rate of root colonisation by DSE was estimated by determining the frequency of brown/dark microsclerotia within cells (\%MS). These latter fungi were hardly stained with the dye but appeared brown to black after root discoloration by $\mathrm{KOH}$. It should be noted that this mea- sure likely underestimates the colonisation rate by DSE; how- ever, it was solely used here as a metric that allows compari- sons among the samples.

\section{Molecular identification of root-colonising fungi}

The identification of fungi living on and/or inside poplar roots was performed as followed. Total DNA was extract- ed from approximately $100 \mathrm{mg}$ of fine roots per sample using the DNeasy Plant Mini Kit (Qiagen S.A.S., Courtabœuf, France). DNAs extracted from 10 root sam- ples of the same area were pooled (equimolar concentra- tions), and the composite sample was diluted 1:25 for PCR amplification. PCR was performed with the ITS1- ITS4 primer set (White et al. 1990) and the Phire® Hot Start II DNA Polymerase (Fisher Scientific, Illkirch, France). PCR products were purified and cloned into the pGEM-T® vector system I (Promega, Charbonnières-les- Bains, France). Amplification products were independent- ly digested with 
MboI and TaqI (New England Biolabs, Ipswich, UK) according to the manufacturer's instruc- tions. Representative RFLP patterns were further selected, and the corresponding plasmid DNAs were sequenced. At least two clones per RFLP pattern were sequenced; the other sequences were classified by RFLP typing.

Sequence similarities were determined using the BLASTN sequence similarity search tool (Altschul et al. 1997). Phylogenetic analyses were carried out using the sequences obtained in this study and those corresponding to the closest matches from GenBank. Sequences were aligned by ClustalW and imported into the Molecular Evolutionary Genetics Analysis (MEGA) package version 6 (Tamura et al. 2013). Phylogenetic analyses were conducted using the Maximum Likelihood (ML) method implemented in MEGA with the pairwise deletion option for handling alignment gaps, and the evolutionary distances were computed using the Kimura 2-parameter method. Bootstrap tests were conducted using 1000 replicates. For the determination of operational taxo- nomic units (OTUs), we used both blastclust (http://toolkit. tuebingen.mpg.de/blastclust) and the rapidOTU pipeline (Legrand et al. 2008) with a $97 \%$ identity threshold. The results were compared with the phylogenetic analyses to de- termine OTUs. DNA sequences obtained in this study were submitted to GenBank and corresponding accession numbers are given in Table 2.

\section{Isolation of root-colonising fungi into pure culture and identification}

To isolate root-inhabiting fungal strains into pure culture, roots were first washed with water, sterilised in $35 \%$ hydro- gen peroxide for $30 \mathrm{~s}$, and rinsed three times in sterile deionised water. About 600 root fragments of approximately $1 \mathrm{~cm}$ were incubated on modified Melin-Norkrans medium (Brundrett et al. 1996), malt extract agar medium (malt: 12 g/l; agar: 15 g/l), NP2/2 medium (Benjdia et al. 2006), or Pachlewski medium (Pachlewski and Pachlewska 1974). The NP2/2 medium (pH 5.5) contained (mg/l): $\mathrm{CaCl}_{2}$ (50), $\mathrm{MgSO}_{4}$ (150), $\mathrm{KH}_{2} \mathrm{PO}_{4}$ (250), $\mathrm{NaH}_{2} \mathrm{PO}_{4}$ (4.5), $\mathrm{Na}_{2} \mathrm{HPO}_{4}$ (160), $\left(\mathrm{NH}_{4}\right)_{2} \mathrm{SO}_{4}$ (250), thiamine hydrochloride (0.04), and glucose (2500). Ampicillin (100 mg/l) and chloramphenicol (100 mg/l) were added to the media to avoid bacterial contam- inations. Dishes were incubated at $25^{\circ} \mathrm{C}$ in the dark from 1 week up to 3 months. Putative endophytic and mycorrhizal isolates were selected and identified via ITS sequencing, and corresponding sequences were aligned with fungal sequences obtained from root samples.

\section{Metal tolerance tests}

The responses of isolates to various concentrations of cadmi- um, copper, lead, or zinc were assessed by growing the iso- lates on MP medium (NP2/2 medium supplemented with $5 \mathrm{~g} / \mathrm{l}$ malt extract, $\mathrm{pH}$ 4.3). MP medium, which allowed the growth of all isolates used in this study, was chosen for consistency. Plugs (5 $\mathrm{mm}$ ) were cut from the actively growing edge of 20-day-old colonies and placed on a sterile EDTA-treated cello- phane membrane, on agar (Fluka, product \#05039) MP medi- um amended with six concentrations of each metal. The con- centrations used were $0,10,50,100,250$, and $500 \mu \mathrm{M} \mathrm{CdCl}_{2} ; 0,0.05,0.1,0.5,1$, and $2 \mathrm{mM} \mathrm{CuCl}_{2} ; 0,0.5,1,2,5$, and $10 \mathrm{mM} \mathrm{Pb}\left(\mathrm{NO}_{3}\right)_{2}$; and $0,1,2,5,10$, and $20 \mathrm{mM} \mathrm{ZnCl}_{2}$.

Colonies were harvested in the late exponential phase of growth, dried at $60^{\circ} \mathrm{C}$, and weighed. Five replicates were performed for each treatment, except for the controls $(n=10)$. For each isolate/metal combination, the minimum inhibitory concentration (MIC) was determined, and growth data were curve-fitted to obtain the effective concentration that inhibited $50 \%$ of mycelial growth $\left(\mathrm{EC}_{50}\right)$.

\section{Growth of the isolates on different carbon sources}

The isolates were tested for their capacity to use different carbon sources. Growth assays were performed

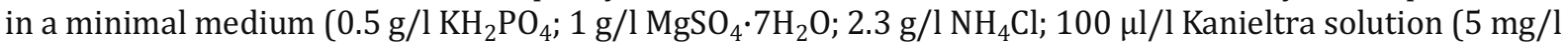
$\mathrm{MnSO}_{4} \cdot 4 \mathrm{H}_{2} \mathrm{O} ; 8.5 \mathrm{mg} / \mathrm{l} \mathrm{H}_{3} \mathrm{BO}_{3} ; 0.3 \mathrm{mg} / \mathrm{l}\left(\mathrm{NH}_{4}\right)_{6} \mathrm{Mo}_{7} \mathrm{O}_{24} \cdot 4 \mathrm{H}_{2} \mathrm{O} ; 6 \mathrm{mg} / \mathrm{FeCl}_{3} ; 0.6 \mathrm{mg} / \mathrm{l} \mathrm{CuSO}{ }_{4} \cdot 5 \mathrm{H}_{2} \mathrm{O} ; 2.7 \mathrm{mg} / \mathrm{l}$ $\mathrm{ZnSO}_{4} \cdot 7 \mathrm{H}_{2} \mathrm{O}$ ), $\mathrm{pH} 5.5$ ) containing $8 \mathrm{~g}$ of one of various compounds as sole carbon source (Table 6). Liquid cultures were shaken at $150 \mathrm{rpm}$ for 3 weeks at $23^{\circ} \mathrm{C}$. For lignin, cellulose, and starch, degradation abilities were considered positive when the isolate showed mycelial development ( $>5 \mathrm{~mm}$ ) around the initial plugs and formation of new small fungal pellets in comparison with the negative control (no carbon). Cellulolytic activities of the isolates were also estimated on agar plates. Isolates were grown for 2 weeks on agar minimal medium containing $5 \mathrm{~g} / \mathrm{l}$ carboxymethyl cel- lulose, and plates were further stained by Congo red 
$(0.1 \% \mathrm{~m} / \mathrm{v})$ and washed three times with $1 \mathrm{M} \mathrm{NaCl}$ in $50 \mathrm{mM}$ phosphate buffer ( $\mathrm{pH}$ 7.0). Cellulase activity was indexed as the diameter of the clear zone (degradation halo) divided by the diameter of the colony.

\section{Re-synthesis experiments between Serenpidita vermifera or Helotiales isolates and poplar clones}

The poplar clone INRA 717-1B4 was used in the present experiment. For in vitro micropropagation, 2-cmlong cuttings from 4-week-old plantlets were grown on Murashige and Skoog medium (pH 5.8) (Murashige and Skoog 1962) in a growth room under controlled conditions $\left(24^{\circ} \mathrm{C} / 18^{\circ} \mathrm{C}, 14 \mathrm{~h} / 10 \mathrm{~h}\right.$ light/dark cycle, light intensity of $660 \mu \mathrm{mol} / \mathrm{m}^{2} / \mathrm{s}$ ). Petri dishes containing Murashige and Skoog medium were pre- pared, and after solidification, one half of the medium was removed. Three-week-old plantlets were transferred to the middle of the plates. The fungal treatments (isolates P02, P04, and P06) contained seven $8 \mathrm{~mm}, 15$-dayold fungal plugs, whereas fungus-free controls were mock-inoculated with agar medium plugs. All experiments were repeated six times. After 2 months of incubation, the plants were harvested, and both shoot and root biomasses were measured. The total number of root tips was measured using the ImageJ software (version 1.47) (Schneider et al. 2012).

\section{Fluorescence microscopy analyses}

Roots from the re-synthesis experiment were analysed for fungal colonisation by epifluorescence microscopy. Selected 1-cm-long root segments were incubated for $10 \mathrm{~min}$ with $5 \mu \mathrm{g} / \mathrm{mL}$ WGA-AF488 (Wheat Germ Agglutinin - Alexa Fluor® 488 conjugate, Molecular Probes) to specifically stain fungal structures. A filter was used to select the wavelength of the excitation light to the $475-500 \mathrm{~nm}$ band, and the fluores- cence emission was recorded above $520 \mathrm{~nm}$. Root autofluo- rescence was observed by using a 405-nm UV lamp and by recording the fluorescence emission in the 420-470 nm band. A Nikon D1 digital camera was used to document results, and the images were visualised and processed with the Image software. Mycelia from pure cultures were also stained with WGA-AF488 and similarly processed by fluorescence microscopy.

\section{Statistical analyses}

Data were analysed with XLSTAT 2011 (Addinsoft, Inc.). To evaluate the $\mathrm{EC}_{50}$, a nonlinear regression analysis was con- ducted with the best-fitted sigmoid equation model. A one- way ANOVA with Tukey's post hoc test $(\mathrm{P}<0.05)$ was used to evaluate significant differences between data in the follow- ing experiments: (i) fungal root colonisation assessment, (ii) $\mathrm{EC}_{50}$ determination (ii) carbon utilisation tests, and (iii) growth responses in the re-synthesis experiments.

\section{Results}

\section{Fungal colonisation of poplar roots at the phytoremediation site}

Because poplar is able to form symbiotic structures with both AM and ECM fungi, both types of mycorrhizal fungi were investigated. Both poplar genotypes were very similarly colonised by ECM fungi (Table 2). Both poplar genotypes were also colonised by AM fungi producing typical arbuscules and vesicles, and colonisation rate and arbuscular density were significantly higher for P. deltoides $\times$ P. nigra compared to $P$. trichocarpa $\times$ P. maximowiczii (Table 2). The DSE fungal structures microsclerotia were also observed on both root hybrids. The intensity of root colonisation by microsclerotia was higher for P. deltoides $\times$ P. nigra when compared to the other clone (Table 2).

The ITS1-ITS4 primer set (White et al. 1990) was used to assess the fungal colonisers of poplar roots from the two hy- brids (Table 2). Overall, a total of 22 fungal operational taxo- nomic units (OTUs) were recovered from poplar roots. Nineteen and 12 OTUs were identified in P. tricho carpa $\times$ P. maximowiczii and in P. deltoides $\times$ P. nigra roots, respectively. Ten were identified in samples from both hy- brids. Ten OTUs were assigned to mycorrhizal fungi by BLAST analyses. Six OTUs belonged to Ascomycota (Peziza, Geopora, Tuber, Helotiales sp.), three to Basidiomycota (Hebeloma) and one to Glomeromycota (Glomus). Among the ascomycetous OTUs, five belonged to the Pezizales. The Peziza genus was the most highly repre- sented and was associated with both poplar genotypes. The OTU belonging to the Helotiales was ambiguously assigned by BLAST analyses either to ericoid mycorrhizal or to ECM fungi from environmental samples, but the 


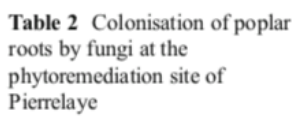

\begin{tabular}{lll}
\hline & $\begin{array}{l}\text { P. trichocarpa } \times \\
P . \text { maximowiczii }\end{array}$ & $\begin{array}{c}\text { P. deltoides } \times \\
P . \text { nigra }\end{array}$ \\
\hline Fungal colonisation & & \\
$\% \mathrm{AM}$ & $13.9 \pm 1.4 \mathrm{a}$ & $22.3 \pm 2.4 \mathrm{~b}$ \\
$\% \mathrm{~A}$ & $2.1 \pm 0.5 \mathrm{a}$ & $5.6 \pm 0.8 \mathrm{~b}$ \\
$\% \mathrm{ECM}$ & $21.1 \pm 3.5 \mathrm{a}$ & $21.1 \pm 2.8 \mathrm{a}$ \\
$\% \mathrm{MS}$ & $1.1 \pm 0.3 \mathrm{a}$ & $3.7 \pm 1.1 \mathrm{~b}$
\end{tabular}

Identification and abundance of fungal OTUs

\begin{tabular}{lllll} 
OTU affiliation & Acc. number & Lifestyle & \multicolumn{2}{l}{ Relative abundance (\%) } \\
Peziza ostracoderma & JX135041 & ECM & 0.93 & 12.82 \\
Peziza sp. & JX135042 & ECM & 1.87 & 7.69 \\
Geopora sp. & JX135043 & ECM & 0.93 & 0.00 \\
Tuber rufum & JX135044 & ECM & 1.87 & 0.00 \\
Geopora cervina & JX135045 & ECM & 0.93 & 0.00 \\
Helotiales sp. & JX135046 & ECM/E & 0.00 & 5.13 \\
H. mesophaeum & JX135047 & ECM & 0.93 & 0.00 \\
H. populinum & JX135048 & ECM & 19.63 & 0.00 \\
H. mesophaeum & JX135049 & ECM & 20.56 & 0.00 \\
Pyrenochaeta sp. & JX135050 & P/E & 15.89 & 6.41 \\
Pythium sp. & JX135051 & P/E & 0.00 & 11.54 \\
Thanatephorus sp. & JX135052 & P/E & 1.87 & 1.28 \\
Ilyonectria sp. & JX135053 & P/E & 0.93 & 0.00 \\
Phoma exigua & JX135054 & P/E & 6.54 & 0.00 \\
Paraphoma chrysanthemicola & JX135055 & E & 5.61 & 0.00 \\
Unc. basal lineage fungus & JX135056 & unkn & 6.54 & 6.41 \\
Mortierella hyalina & JX135057 & S & 0.93 & 0.00 \\
Tetracladium sp. & JX135058 & P/E & 10.28 & 28.21 \\
Rhizoctonia sp. & JX135059 & P/E & 0.93 & 7.69 \\
Ceratobasidium sp. & JX135060 & P/E & 1.87 & 6.41 \\
Psathyrella sp. & JX135061 & S & 0.00 & 1.28 \\
Glomus sp. & JX135062 & AM & 0.93 & 5.13 \\
\hline
\end{tabular}

Values are expressed as the means $(n=40) \pm \mathrm{SE}$, and within a row, significant differences $(P<0.05$, ANOVA, followed by Tukey's test) are indicated by different letters

$\% A M$ rate of arbuscular mycorrhizal colonisation, $\% A$ arbuscular density, $\% E C M$ rate of ectomycorrhizal colonisation, $\% M S$ microsclerotia frequency, $U n c$. uncultured, $E$ endophytic, $P$ parasitic, $S$ saprotrophic, unk unknown

lifestyle of this species remains unknown. Hebeloma was the only ECM ba- sidiomycetous genus recovered from this analysis. Non- mycorrhizal fungal taxa, such as saprotrophic or endophytic/ parasitic fungi, were also identified from poplar roots (Table 2). These fungi belonged either to Ascomycota or Basidiomycota. The most represented saprotrophic, parasitic or endophytic fungal OTUs were Ceratobasidium sp., Tetracladium sp., Rhizoctonia sp., and Pyrenochaeta sp..

\section{Isolation and taxonomic assignment of fungal strains}

The isolation protocol allowed us to obtain a final set of 38 fungal colonies corresponding to putative mycorrhizal spe- cies. After redundancy checking (comparison of ITS se- quences), 8 fungal isolates were definitively selected for sub- sequent experiments (Table 3 ).

Table 3 Pure culture mycorrhizal and endophytic isolates from poplar roots

\begin{tabular}{lllll}
\hline Isolates & Taxonomic affiliation & \multirow{2}{*}{ Lifestyle } & \multicolumn{2}{l}{ Nearest blast hit } \\
\cline { 3 - 5 } & & & Acc. number & Identity (\%) \\
\hline P14 & Hebeloma populinum & ECM & JX135073 & 99 \\
P17 & Hebeloma populinum & ECM & JX135048 & 99 \\
P33 & Hebeloma populinum & ECM & JX135068 & 99 \\
P13 & Hebeloma mesophaeum & ECM & JX135048 & 99 \\
P23 & Hebeloma mesophaeum & ECM & JX135072 & 99 \\
P06 & Helotiales new clade & unkn & JX135046 & 98 \\
P02 & Helotiales new clade & unkn & JX135046 & 96 \\
P04 & Serendipita vermifera & unkn & JX135065 & 99 \\
\hline
\end{tabular}

ECM ectomycorrhizal, unkn unknown 
Five isolates belonged to the Hebeloma genus (P13, P14, P17, P23, P33), two to an un- known species of the Helotiales (P02, P06), and one to the Sebacinales (P04). ITS sequences were further compared with those obtained through the OTU analysis together with those previously pub- lished. Phylogenetic trees were then constructed based on phylogenies of the Hebeloma genus (Boyle et al. 2006) (Fig. 1), the Sebacinales (Riess et al. 2014) (Fig. 2) and the Helotiales (Wang et al. 2006) (Fig. 3).

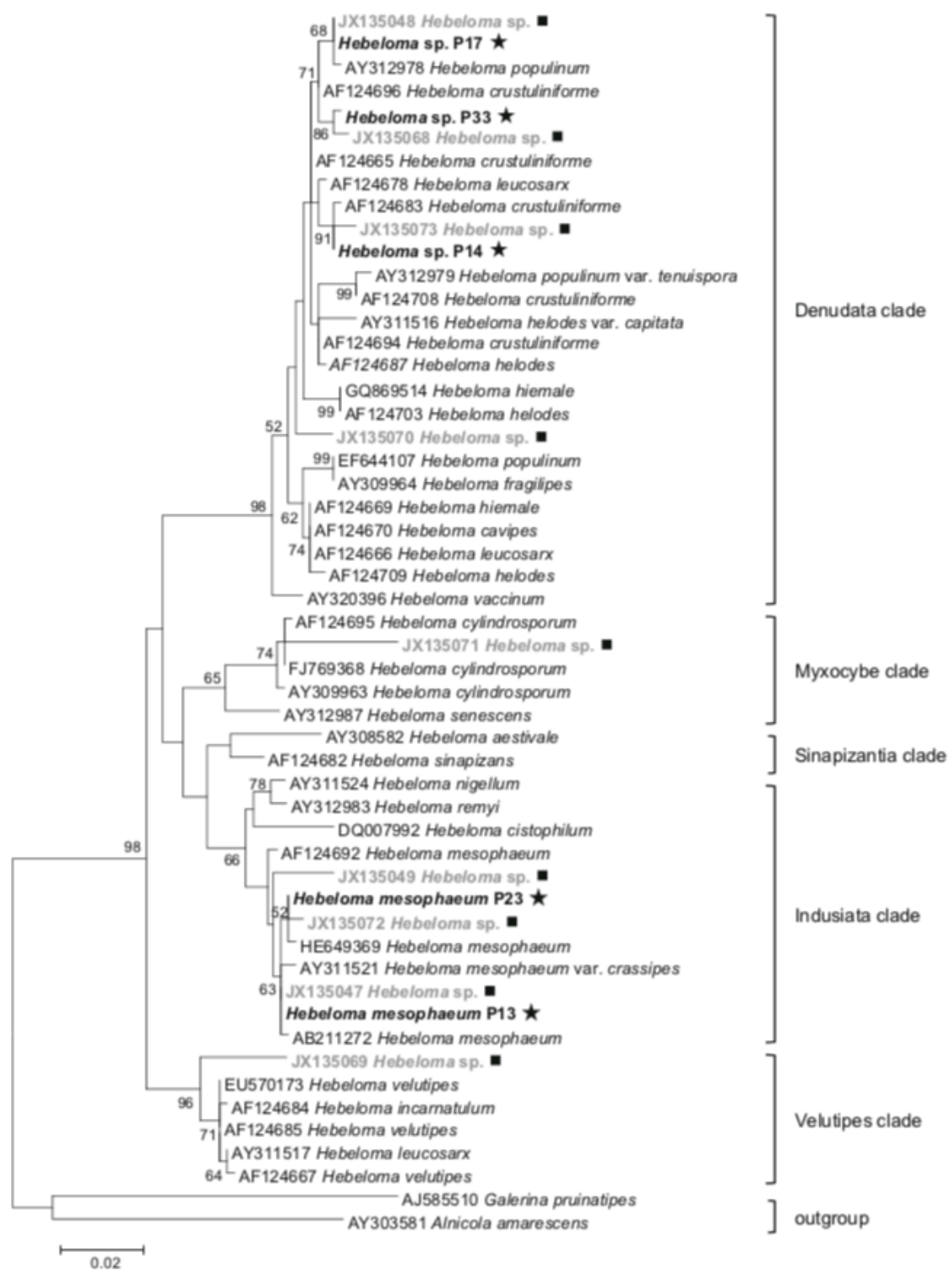

Fig. 1 Maximum Likelihood phylogenetic tree based on rDNA ITS sequence data from Hebeloma OTUs identified by ITS-RLFP analysis (squares) or pure culture strains isolated from poplar roots (stars) with known and selected fungal species from GenBank with high sequence similarities. Bootstrap values over $50 \%$ (1000 replicates) are indicated above the branches. The different clades described by Boyle et al. (2006) are represented

The ITS sequences of the five Hebeloma isolates P13, P14, P17, P23 and P33 that originated from the Pierrelaye site matched with the OTUs previously identified from roots (JX135047, JX135073, JX135048, JX135072 and JX135068, respectively) (Fig. 1, Table 3). The phyloge- netic analysis divided the five isolates within two major clades in which several Hebeloma species clustered to- gether (Fig. 1). More particularly, these results suggested that P14, P17 and P33 belonged to the Hebeloma denudata clade, whereas P13 and P23 belonged to the Hebeloma indusiata clade.

The ITS sequence of the P04 isolate was closely related to the OTU JX135065, previously identified from poplar roots by using a basidiomycetous-specific primer set (ITS1F-ITS4B) in a preliminary experiment (data not shown). Both sequences clustered into clade B of the Sebacinales phylogenetic tree and were closely related to the S. vermifera species (Fig. 2, Table 3). Other environ- mental sequences of Sebacinales 
retrieved from GenBank, previously identified from poplar roots, were also used to construct the phylogenetic tree, but all clustered within clade A (Fig. 2). When grown on MP medium, S. vermifera P04 appeared white and slightly glossy with regular margins. Hyphae were cylindrical, thin-walled and transparent. With age, monilioid cells, smooth and colourless, appeared (Fig. 4a, d).
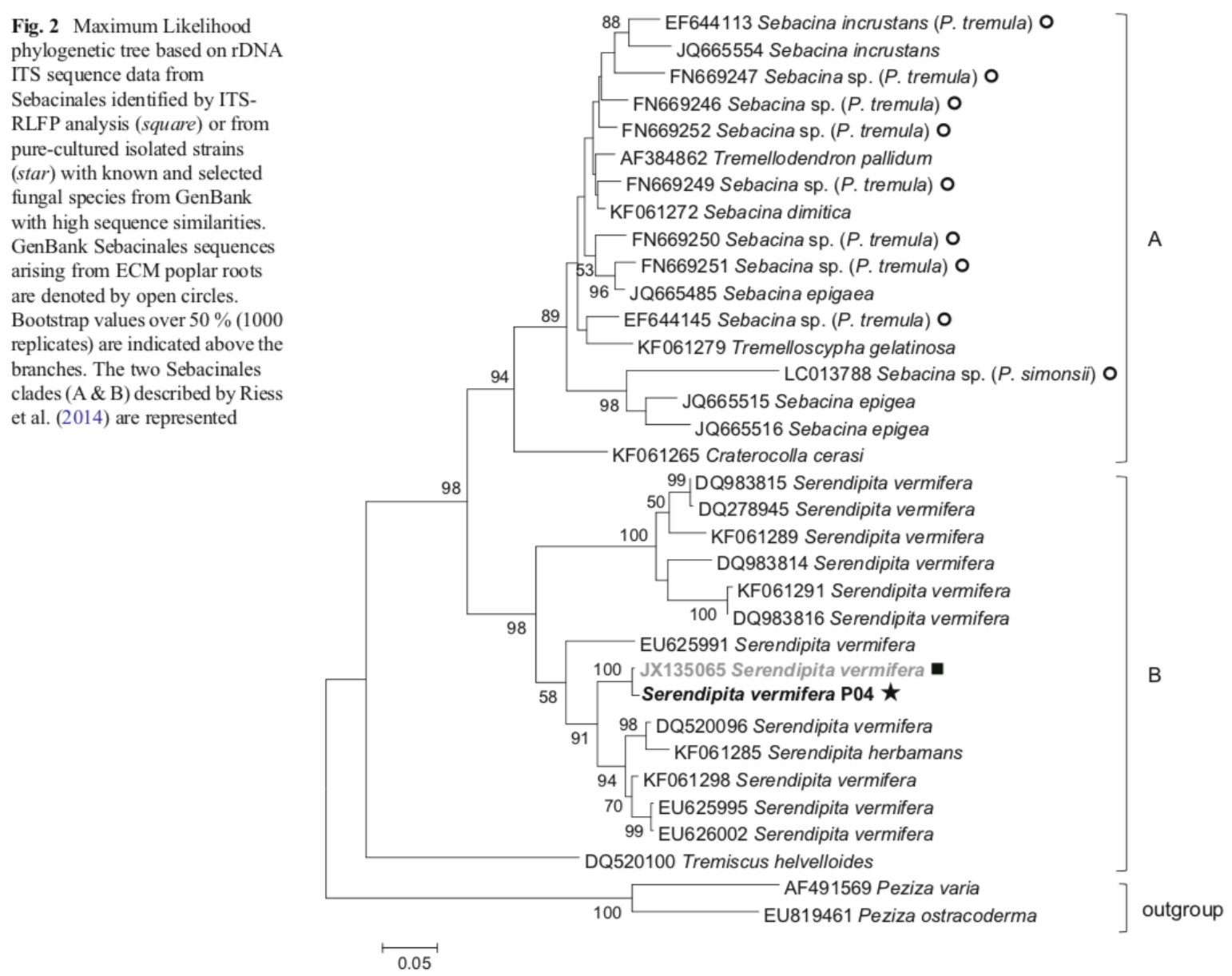

Fig.2 MaximumLikelihood phylogenetic tree based on rDNA ITS sequence data from Sebacinales identified by ITS- RLFP analysis (square) or from pure-cultured isolated strains (star) with known and selected fungal species from GenBank with high sequence similarities. GenBank Sebacinales sequences arising from ECM poplar roots are denoted by open circles. Bootstrap values over 50 $\%$ (1000 replicates) are indicated above the branches. The two Sebacinales clades (A \& B) described by Riess et al. (2014) are represented.

The ITS sequences of the isolates P02 and P06 shared $97 \%$ identity and were closely related to the fungal OTU JX135046, previously identified from poplar roots. The phylogenetic analysis of Helotiales revealed that P02 and P06 clustered in a new clade, not described by Wang et al. (2006). This new clade was closely related to the Leohumicola clade (Fig. 3). BLAST searches allowed us to retrieve other ITS sequences

belonging to this new clade. These sequences arose from either soil or root environmental samples, but none from isolated strains. These taxa were identified from a variety of plants (ligneous or herbaceous) from different continents (America, Asia, Europa and Oceania) (Fig. 3). On MP medium, colonies of the Helotiales P06 and P02 were white to cream-coloured with an irregular surface. Aging hyphae of Helotiales P02 and P06 turned green after 7 and 21 days of growth, respectively (Fig. 4b, c). Hyphae were cylindrical and thin-walled. With aging, the cells and hy- phae of Helotiales P02 and P06 became swollen and formed a chain of spherical spore-like structures (Fig. 4e, f).

\section{Metal tolerance assays}

The $\mathrm{EC}_{50}$ and MIC values were determined for the iso- lates on a set of four metals (Table 4). Metal tolerance of the fungal isolates varied between isolates and metal spe- cies. The Helotiales P02 and P06 isolates exhibited the highest tolerance to $\mathrm{Cd}, \mathrm{Cu}, \mathrm{Pb}$ and $\mathrm{Zn}$ compared to the other isolates, whereas the isolates 


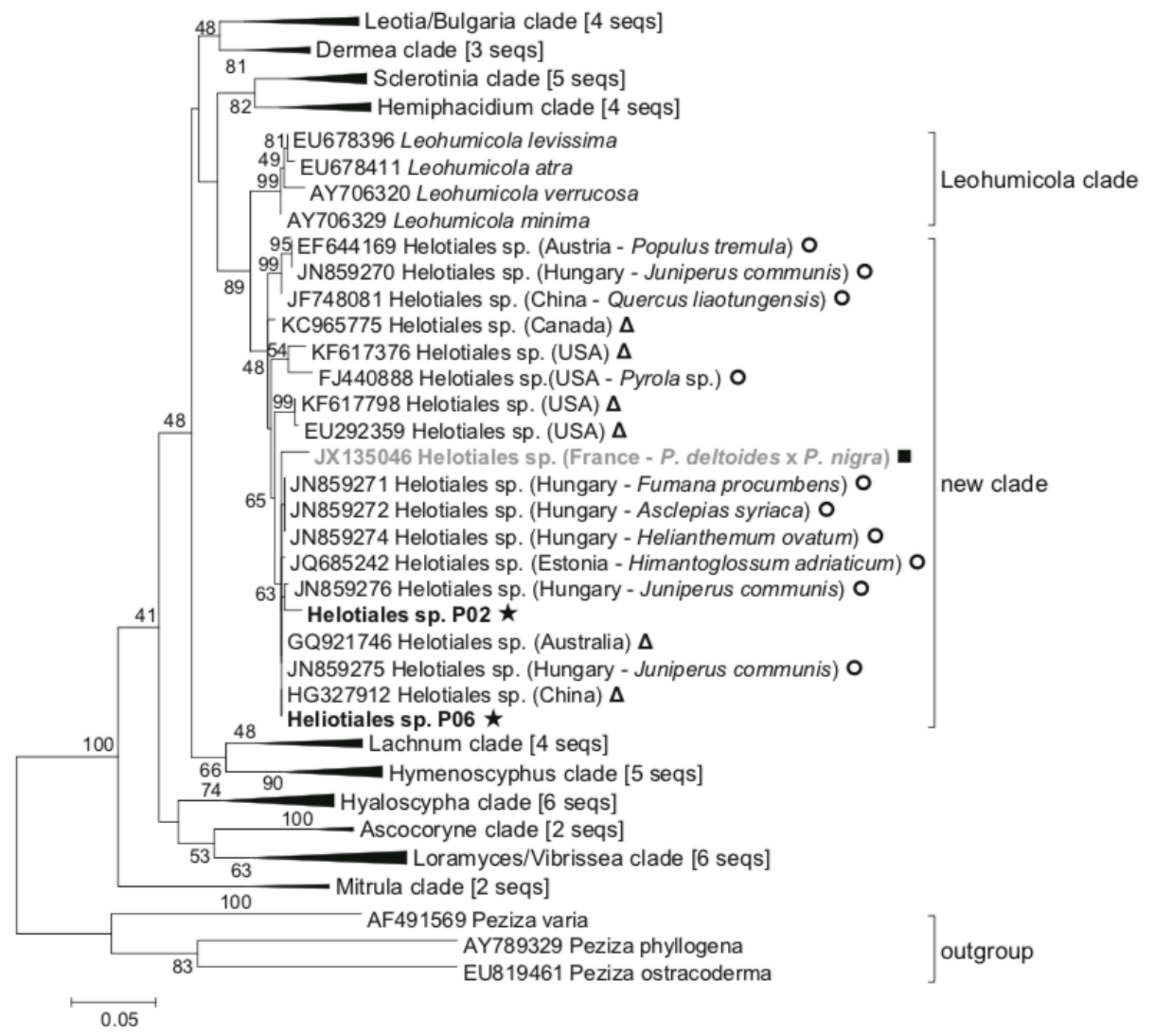

Fig.3 MaximumLikelihood phylogenetic tree based on rDNA ITS sequence data from Helotiales identified by ITS- RLFP analysis (square) or from pure-cultured isolated strains (stars) with known and selected fungal species from GenBank with high sequence similarities. Sequences retrieved from GenBank derived from either soil samples (open triangles) or roots of diverse plants (open circles), and both the origin and the name of the host plant are given in brackets. Bootstrap values over $40 \%$ (1000 replicates) are indicated above the branches. The different clades described by Wang et al. (2006) are represented and are compressed for simplicity. For each grouping, the number of sequences contained within is provided in square brackets, and a representative genus is indicated.

P13 and P23 (belong- ing to the H. denudata clade) exhibited a weak tolerance to the metals tested. The $\mathrm{EC}_{50}$ of the isolates of the $\mathrm{H}$. indusiata clade (P14, P17 and P33) were similar to those of P13 and P23 but were slightly higher. The S. vermifera P04 isolate presented a moderate tolerance to $\mathrm{Cd}$ and $\mathrm{Cu}$.

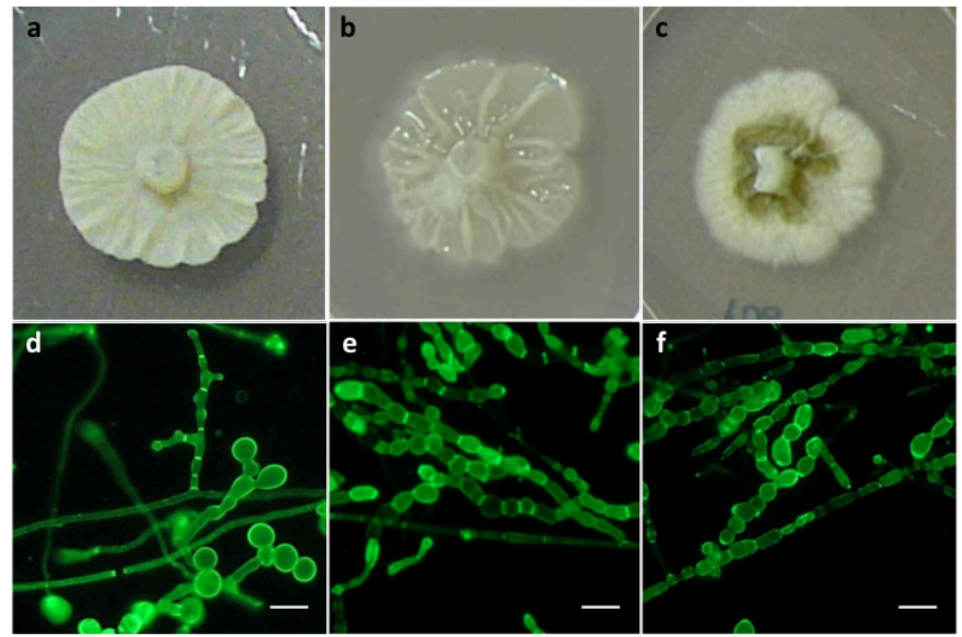

Fig.4 Morphological characteristics of the fungal isolates Serendipita vermifera P04, Helotiales P02 and Helotiales P06. a Colony of S. vermifera P04 at day 30; b colony of Helotiales P06 at day 15; c colony of Helotiales P02 at day 15; d cylindrical and monilioid hyphae without clamps of S. vermifera P04; e hyphal branching and monilioid cells of Helotiales P06; $\mathrm{f}$ hyphal branching and monilioid cells of Helotiales P02. The hyphae were stained with WGA-AF488 and observed under a fluorescence microscope. Scale bars $=15 \mu \mathrm{m}$ 
Lifestyles of the Helotiales P02 and P06 isolates and the S. vermifera P04 isolate

Table4 Metal tolerance of the isolates

\begin{tabular}{|c|c|c|c|c|c|c|c|c|}
\hline \multirow[t]{2}{*}{ Isolates } & \multicolumn{4}{|l|}{$\mathrm{EC}_{50}{ }^{\mathrm{a}}(\mathrm{mM})$} & \multicolumn{4}{|c|}{$\mathrm{MIC}^{\mathrm{b}}(\mathrm{mM})$} \\
\hline & $\mathrm{Cd}$ & $\mathrm{Cu}$ & $\mathrm{Pb}$ & $\mathrm{Zn}$ & $\mathrm{Cd}$ & $\mathrm{Cu}$ & $\mathrm{Pb}$ & $\mathrm{Zn}$ \\
\hline P14 & $0.08 \pm 0.02 \mathrm{bc}$ & $0.15 \pm 0.00 \mathrm{c}$ & $0.81 \pm 0.03 \mathrm{de}$ & $0.85 \pm 0.07 \mathrm{~d}$ & 0.25 & 0.5 & 2.0 & 5.0 \\
\hline P17 & $0.09 \pm 0.03 \mathrm{bc}$ & $0.14 \pm 0.04 \mathrm{c}$ & $1.08 \pm 0.14 \mathrm{c}$ & $1.07 \pm 0.01 \mathrm{~d}$ & 0.25 & 1.0 & 2.0 & 2.0 \\
\hline P33 & $0.24 \pm 0.02 \mathrm{bc}$ & $0.24 \pm 0.03 \mathrm{c}$ & $0.96 \pm 0.13 \mathrm{~cd}$ & $1.34 \pm 0.11 \mathrm{~d}$ & $>0.5$ & 1.0 & 2.0 & 5.0 \\
\hline P13 & $0.02 \pm 0.01 \mathrm{c}$ & $0.07 \pm 0.01 \mathrm{c}$ & $0.56 \pm 0.01 \mathrm{f}$ & $1.40 \pm 0.42 \mathrm{~cd}$ & 0.25 & 0.5 & 2.0 & 5.0 \\
\hline P23 & $0.01 \pm 0.00 \mathrm{c}$ & $0.10 \pm 0.03 \mathrm{c}$ & $0.61 \pm 0.23$ ef & $0.85 \pm 0.12 \mathrm{~d}$ & 0.05 & 0.5 & 2.0 & 2.0 \\
\hline P06 & $>0.5 \mathrm{a}$ & $1.96 \pm 0.26 \mathrm{a}$ & $3.82 \pm 0.15 b$ & $6.19 \pm 0.60 \mathrm{~b}$ & $>0.5$ & $>2.0$ & 10 & 20 \\
\hline P02 & $>0.5 \mathrm{a}$ & $2.00 \pm 0.25 \mathrm{a}$ & $5.07 \pm 0.05 \mathrm{a}$ & $9.50 \pm 0.48 \mathrm{a}$ & $>0.5$ & $>2.0$ & 10 & 20 \\
\hline P04 & $0.33 \pm 0.01 \mathrm{~b}$ & $0.70 \pm 0.02 b$ & $1.06 \pm 0.01 \mathrm{c}$ & $1.94 \pm 0.15 \mathrm{c}$ & $>0.5$ & 2.0 & 2.0 & 5.0 \\
\hline
\end{tabular}

${ }^{a} \mathrm{EC}_{50}$ is the effective concentration of metals that inhibited mycelial growth by $50 \%$; sigmoid curves were fitted to the growth data (dry weight), and $\mathrm{EC}_{50}$ were deduced. Values are expressed as the means of 3 biological replicates \pm SD. Statistically significant differences $(P<0.05$, ANOVA, followed by Tukey's test $)$ are indicated by different letters

${ }^{\mathrm{b}} \mathrm{MIC}$ is defined as the minimum inhibitory concentration of metals that completely inhibited fungal growth

A re-synthesis experiment with the S. vermifera P04 iso- late and the Helotiales P02 and P06 isolates was conduct- ed to obtain structural and functional evidence of the my- corrhizal or endophytic status of these isolates. Our ex- perimental interaction assays demonstrated that two iso- lates had positive effects on poplar (Table 5). Poplar cut- tings inoculated by P02 and P04 showed a more extensive root branching pattern when compared to the mock- inoculated plants. The number of root tips indeed doubled in the presence of the fungal inocula. When compared to the control plants, both root and shoot fresh weights of poplar inoculated by the Helotiales isolates were not af- fected. Inoculation by S. vermifera P04 did not modify root fresh weight. However, the shoot fresh weight signif- icantly increased by $15 \%$ in the presence of S. vermifera P04 compared to mock-inoculated plants (Table 5).

Table 5 Effect of fungal inoculation on in vitro growth of poplar cuttings

\begin{tabular}{llll}
\hline Treatment & SFW (mg/plant) & RFW (mg/plant) & Number of root tips \\
\hline Control & $137.7 \pm 15.3 \mathrm{a}$ & $15.9 \pm 2.6 \mathrm{a}$ & $14.2 \pm 2.9 \mathrm{a}$ \\
P02 & $117.8 \pm 17.6 \mathrm{a}$ & $21.7 \pm 4.9 \mathrm{a}$ & $28.0 \pm 4.9 \mathrm{ab}$ \\
P04 & $158.4 \pm 17.7 \mathrm{~b}$ & $16.6 \pm 4.9 \mathrm{a}$ & $28.3 \pm 2.9 \mathrm{~b}$ \\
P06 & $124.6 \pm 11.5 \mathrm{a}$ & $21.1 \pm 2.5 \mathrm{a}$ & $33.3 \pm 7.2 \mathrm{~b}$ \\
\hline
\end{tabular}

Cuttings were grown for 2 months on agar Murashige \& Skoog medium. Values are the means of six replicates \pm SE. Statistically significant differences ( $P<0.05$, ANOVA, followed by Tukey's test) are indicated by different letters

$S F W$ shoot fresh weight, $R F W$ root fresh weight, control mock-inoculated poplar cuttings

Roots were labelled with WGA-AF488, a fungus- specific dye, and further analysed by epifluorescence microscopy. Our observations confirmed the lack of fungal hyphae/structures in roots of the mock-inoculated plants. When inoculated by Helotiales P02, roots were covered by hyphae but no fungal structures could be observed within roots (data not shown). In contrast, numerous microsclerotia-like structures were observed within roots of plants inoculated by S. vermifera P04 (Fig. 5a, b) or Helotiales P06 (Fig. 5c, d). 
These structures were only detected in the cortical cell layer and not in the endoder- mis nor in the central cylinder (Fig. 5). The hyphae of the microsclerotia were thin-walled, non-coloured, septate and usually tightly packed within root cells. In some cases, microsclerotia formed by S. vermifera P04 were sparsely packed (Fig. 5a).
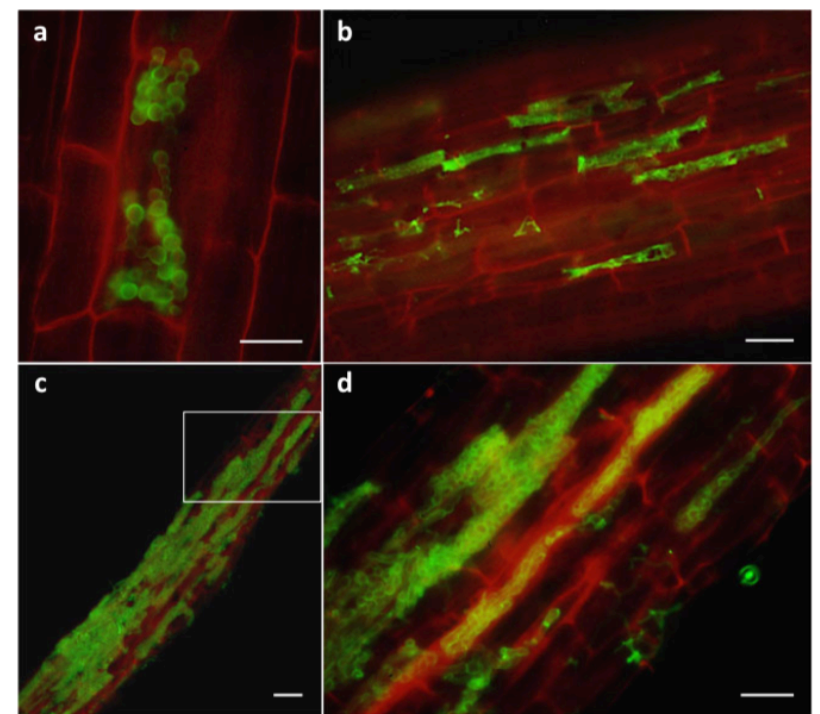

Fig.5 Fungalstructuresof Serendipita vermifera P04 (a, b) and Helotiales P06 (c, d) within poplar roots. Hyphae were stained with WGA-AF488. Plant tissues are displayed in red and fungal tissues in green. The white rectangle indicates the location of the enlarged zone displayed in $\mathrm{d}$. Scale bars $=20 \mu \mathrm{m}$

\section{Growth of the isolates on different carbon sources}

The ability of P02, P04 and P06 to use various simple and complex carbon substrates was investigated by growing them in liquid cultures with various substrates as sole carbon source. Piriformospora indica was used as an endophytic ref- erence. Cellulose, starch and lignin substrates were insoluble and adhered to the hyphae at the time of harvesting, increasing the apparent biomass yield of all isolates on these substrates. For this reason, growth on these three carbon sources was not compared to other substrates. From visual observations of these treatments, however, it was possible to qualitatively de- termine whether mycelial growth was higher than in the non- carbon treatment.

Table 6 Growth of the isolates on different carbon sources

\begin{tabular}{|c|c|c|c|c|}
\hline \multirow[t]{2}{*}{ Substrate } & \multicolumn{4}{|l|}{ Isolate } \\
\hline & $\mathrm{P} 02$ & P04 & P06 & P. indica \\
\hline $\mathrm{CMC}$ & $44.4 \pm 1.9 \mathrm{~g}$ & $38.6 \pm 1.2 \mathrm{~d}$ & $47.5 \pm 1.6 \mathrm{e}$ & $41.9 \pm 3.0 \mathrm{fg}$ \\
\hline Cellobiose & $79.4 \pm 5.9 \mathrm{abc}$ & $40.2 \pm 3.2 \mathrm{c}$ & $120.4 \pm 11.3 \mathrm{ab}$ & $57.5 \pm 0.6 \mathrm{de}$ \\
\hline Fructose & $72.0 \pm 1.6 \mathrm{cde}$ & $67.4 \pm 0.5 \mathrm{~b}$ & $104.7 \pm 1.88 \mathrm{abc}$ & $60.1 \pm 2.6 \mathrm{~cd}$ \\
\hline Glucose & $111.1 \pm 15.8 \mathrm{a}$ & $68.2 \pm 8.0 \mathrm{~b}$ & $147.1 \pm 15.8 \mathrm{a}$ & $71.5 \pm 3.4 \mathrm{ab}$ \\
\hline Maltose & $76.5 \pm 1.7 \mathrm{bcd}$ & $78.2 \pm 5.5 \mathrm{~b}$ & $102.7 \pm 28.6 \mathrm{abcd}$ & $64.8 \pm 0.2 \mathrm{ab}$ \\
\hline Mannitol & $67.1 \pm 7.3 \mathrm{def}$ & $23.4 \pm 2.5 \mathrm{~d}$ & $93.6 \pm 2.3 \mathrm{abcd}$ & $18.2 \pm 1.3 \mathrm{~g}$ \\
\hline Sucrose & $85.6 \pm 1.8 \mathrm{ab}$ & $78.6 \pm 6.9 \mathrm{~b}$ & $82.6 \pm 19.0 \mathrm{~cd}$ & $73.6 \pm 3.6 \mathrm{a}$ \\
\hline Xylan & $66.8 \pm 2.6$ ef & $103.2 \pm 2.0 \mathrm{a}$ & $134.0 \pm 26.8 \mathrm{ab}$ & $71.8 \pm 7.4 \mathrm{ab}$ \\
\hline Xylose & $60.0 \pm 6.2 \mathrm{fg}$ & $38.9 \pm 1.0 \mathrm{~d}$ & $64.4 \pm 5.7 \mathrm{de}$ & $46.4 \pm 1.7$ ef \\
\hline Cellulose ${ }^{\mathrm{a}}$ & + & - & + & + \\
\hline Lignin $^{\mathrm{a}}$ & + & - & - & - \\
\hline Starch $^{\mathrm{a}}$ & + & + & + & + \\
\hline
\end{tabular}

Values are expressed as the means (mg dry weight) of 3 biological replicates \pm SD. Liquid cultures were harvested after 3 weeks of growth. Statistically significant differences $(P<0.05$, ANOVA, followed by Tukey's test) are indicated by different letters

CMC carboxymethyl-cellulose

a Due to the insolubility of these compounds, only qualitative growth of the fungi was recorded (+: growth, -: absence of growth)

Growth of P. indica was optimal on glucose, sucrose and xylan, but poor on CMC, xylose and especially mannitol (Table 6). The response pattern of S. vermifera P04 to the different carbon substrates was similar to that of P. indica. The only exception was the absence of growth on cellulose for S. vermifera P04. Growth 
of Helotiales P06 was higher than that of Helotiales P02 on most carbon sources. Growth of both isolates was optimal on glucose-amended media but poor on CMC- or xylose-supplemented media. However, Helotiales P02 and P06 slightly differed in their utilisation patterns of the other carbon sources. When compared to Helotiales P02, Helotiales P06 grew better on cellobiose, maltose and xylan. Surprisingly, moderate growth of Helotiales P02 was observed on lignin-containing medium (Table 6). To confirm the cellulose degradation ability of the different isolates, another experiment was set up on agar me- dium to confirm the degradation of CMC. A CMC solubilisation halo was observed after Congo red staining of the plates. S. vermifera P04 produced a small halo below the centre of the fungal colony (Fig. 6). Large halos were ob- served in the presence of Helotiales P02 and P06, and to a lesser extent with P. indica. The largest degradation halo was induced by Helotiales P02 (Fig. 6).

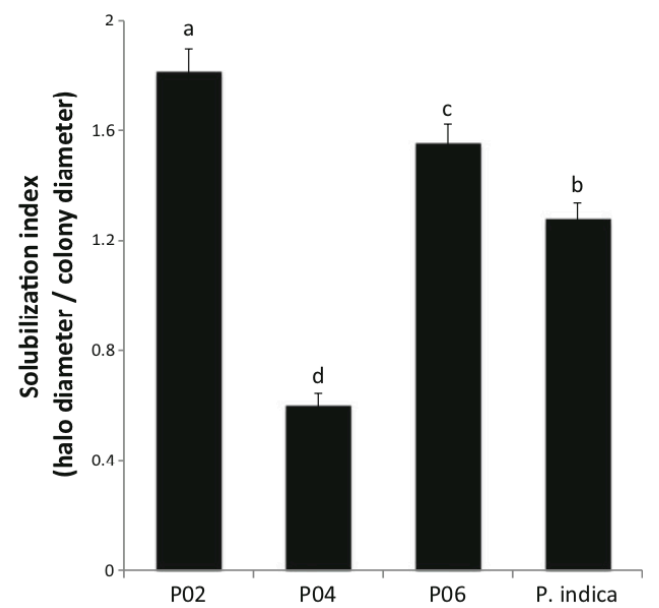

Fig. 6 Carboxy-methyl cellulose solubilisation by the endophytic isolates. The solubilisation index was calculated as the ratio between the diameter of the solubilisation halo and the diameter of the colony. Piriformospora indica was used as reference. Values are the means of three replicates \pm SE. Statistically significant differences $(P<0.05$, ANOVA, followed by Tukey's test) are indicated by different letters.

\section{Discussion}

\section{Fungi associated with poplar roots from a metal-contaminated site}

We identified both endophytic and mycorrhizal (AM and ECM) fungi from poplar roots. Similar colonisation rates were reported for several poplar clones from contaminated soils, although higher ECM colonisation rates are often reported (Khasa et al. 2002; Gehring et al. 2006; Karliński et al. 2010). However, those data were derived from studies with older trees, and poplar preferentially associates with AM spe- cies during the first years of growth. This statement was con- firmed by the analysis of poplar root colonisation over time from our experimental site (Chalot et al., unpublished data).

In the present study, the number of fungal OTUs was con- sistent with that reported in a study focusing on the fungal diversity of poplar roots from a metal-polluted soil using the same molecular method (Krpata et al. 2008). The AM fungal taxa we identified belonged to the Glomus genus. This genus is widespread in metal-contaminated environments (Turnau et al. 2001; Vallino et al. 2006; Zarei et al. 2008), suggesting that these Glomus species could be metal tolerant. We also identified ECM OTUs belonging to Peziza, and Hebeloma, as reported in different studies investigating fungal communities from poplar roots (Krpata et al. 2008; Stefani et al. 2009; Hrynkiewicz et al. 2010; Danielsen et al. 2013; Karliński et al. 2013; Bonito et al. 2014). Notably, Krpata et al. (2008) found species belonging to the genera Peziza, Laccaria, Tuber, Sebacina and Hebeloma along with several ericoid mycorrhizal fungi in the roots of Populus tremula sampled from a metal-polluted $(\mathrm{Pb}, \mathrm{Zn}$ and $\mathrm{Cd})$ site.

Endophytic fungi are involved in the phytostabilisation processes of the plants that they are associated with. The plant growth-promoting DSE isolate DB146 has been used to en- hance the establishment and growth of willow (Salix caprea) in a metal-contaminated soil (Likar and Regvar 2013). Interestingly, one 
undetermined fungus belonging to the Helotiales was also identified in our study and was assigned to either ECM or endophytic fungi according to the different blast results. Moreover, three putative endophytic isolates were established in pure culture and were further studied.

\section{Metal tolerance of the isolates}

The identification of fungi that could form symbiotic associa- tion with poplar roots is a prerequisite to any fungal-based bioaugmentation trial. One of our objectives was therefore to isolate some of the major mutualistic species associated with poplar from this metal-enriched environment. Metal-tolerant strains better protect host plants against metal toxicity, wheth- er they are mycorrhizal (Adriaensen et al. 2005; Redon et al. 2009; Colpaert et al. 2011) or endophytic fungi (Shahabivand et al. 2012; Likar and Regvar 2013). Therefore, the different isolates were screened for their tolerance levels on a set of metals.

The Helotiales P02 and P06 isolates were the most tolerant to metals, while S. vermifera P04 was moderately tolerant and Hebeloma isolates were the least tolerant. Interspecific varia- tions have been demonstrated in a number of studies of axe- nically cultured ECM or endophytic fungi (Blaudez et al. 2000; Ray et al. 2005; Fomina et al. 2005; Ban et al. 2012), which may be due to the presence or absence of different tolerance mechanisms within the different isolates, or to dif- ferential expression levels of genes/proteins involved in these mechanisms (Bellion et al. 2006). Interestingly, when metal contamination increases at an experimental site, mycorrhizal colonisation of S. caprea roots decreases while colonisation by DSE fungi was not affected (Likar and Regvar 2009; Regvar et al. 2010). Thus, considering the high metal toler- ance of the endophytic isolates compared to the mycorrhizal isolates, we focused on the former to determine their lifestyle and capacity to improve plant growth.

\section{Characterisation of new endophytic isolates of poplar roots}

The nearest BLAST matches poorly assigned the fungal iso- lates P02, P04 and P06 as Buncultured mycorrhizal fungus from environmental samples^. However, in literature, mem- bers of the Helotiales or Sebacinales have been described as endophytes, mycorrhiza-forming fungi or even plant patho-gens (Wang et al. 2006; Selosse et al. 2009). A set of experi- ments including phylogenetic analyses, morphological observations, capacity to use various carbon substrates and a re- synthesis experiment with poplar cuttings were conducted to address their mycorrhizal or endophytic status.

Sebacinales can be endophytic, ECM, ericoid mycorrhizal, ectendomycorrhizal, or orchid mycorrhizal (Selosse et al. 2009; Oberwinkler et al. 2013). To our knowledge, only ECM associations between Sebacinales and Salicaceae have been reported (Oberwinkler et al. 2013). Moreover, ECM Sebacinales only clustered into clade A (Fig. 2); while S. vermifera P04 clustered into clade B, whose members are either endomycorrhizal fungi of autotrophic orchids and Ericaceae, or endophytic of liverworts (Selosse et al. 2009). Morphologically, hyphae and pure culture colonies of S. vermifera P04 resemble those of Serendipita herbamans, an endophytic fungus, also clustered into clade B (Riess et al. 2014). Growth of S. vermifera P04 on the various carbon sources was similar to that of P. indica, a well-known biotrophic fungus from Sebacinales. S. vermifera P04 was able to use cell wall-related carbohydrates, indicating the pro- duction of cellulolytic enzymes, suggesting that this fungus could also act as an endophyte colonising root cells. In our re- synthesis experiments, S. vermifera P04 formed microsclerotia-like structures within poplar roots. Moreover, poplar root development and shoot biomass were stimulated in inoculated plants compared to mock-inoculated controls. We therefore provide the first evidence that $\mathrm{S}$. vermifera is a growth-promoting endophyte of poplar.

Members of the Helotiales have a wide range of lifestyles and have been described as plant pathogens, endophytes, nematode-trapping fungi, mycorrhiza-forming fungi, fungal or ECM parasites, saprobes and wood rot fungi (Wang et al. 2006). In this study, two isolates (P02 and P06) belonging to the Helotiales were grown in pure culture. Their ITS se- quences presented $97 \%$ identity. This result suggests that P02 and P06 might belong to the same species or to two closely related species. These two isolates were closely related to fungi isolated from various plants, woody or herbaceous and from various continents. In this regard, this taxon seems to be widely distributed. The ITS sequences of the P02 and P06 isolates clustered into a new clade within the Helotiales, but diverged from the accession sequences of Leohumicola spe- cies included in the analysis. Therefore, Helotiales P02 and P06 could belong to either a new species or a previously morphologically described species for which no molecular data exists. The DSE isolate DB146, closely 
related to the Leohumicola genus, was highly tolerant to $\mathrm{Zn}$ and $\mathrm{Pb}$ and improved the growth and the tolerance of S. caprea cuttings in a metal-enriched soil (Likar and Regvar 2013). The isolate P06 stimulated root development of poplar in vitro, even if root biomass was not affected. These isolates were highly tolerant in vitro and could potentially protect host plants against metal-induced toxic effects, as earlier demonstrated for endophytic (Shahabivand et al. 2012; Likar and Regvar 2013) and mycorrhizal (Adriaensen et al. 2005; Redon et al. 2009; Colpaert et al. 2011) fungi. However, further plant ex- periments, including metal-contaminated soils and dose re- sponse analyses, will be required to demonstrate whether the symbiosis with these new endophytes would have a stronger effect on plant health than a symbiosis with ECM fungi such as Hebeloma sp. under heavy metal exposure. Particularly, endophytic and mycorrhizal fungi should be included, in sin- gle and mixed inoculations. The P02 and P06 isolates also degraded different cell wall-related carbohydrates, suggesting that production of fungal cellobiohydrolases, endoglucanases and $\beta$-glucosidases may enable complete hydrolysis of cellu- lose to glucose. The complete use of cellulose is unsurprising, as these enzymes are presumably required for host cell pene- tration (Smith and Read 2008). Moreover, from our re- synthesis experiments, P06 seemed to be an endophyte of poplar roots, as demonstrated by the presence of hyphae and microsclerotia within root cells. Such structures were not iden- tified within roots colonised by Helotiales P02 and this strain could: (i) be incompatible with the poplar hybrid we have used, (ii) be a casual rhizosphere inhabitant, or (iii) request different experimental conditions to associate with poplar roots. However, further experiments will be necessary to dem- onstrate the lifestyle of this isolate.

\section{Conclusions and perspectives}

Our results advance the understanding of fungal diversity as- sociated with poplar in metal-polluted sites. The metal- tolerant isolates may be considered novel root endophytes of poplar. S. vermifera P04 could be a promising candidate to assist poplar growth in contaminated environments. However, further inoculation experiments in metal-polluted soils should be tested prior to its use in phytoremediation field trials. We already demonstrated that poplar growth, in large-scale plan- tations, was enhanced through inoculation with AM fungi at the same metal-polluted site (Chalot et al. unpublished data). The inoculation of poplar by endophytic consortia could be used as a new strategy for tree-based phytoremediation pro- jects. Further experiments will be needed to assess whether S. vermifera P04 also has the potential to promote growth of a wide range of terrestrial plants, including food crops, as dem- onstrated for P. indica.

\section{Acknowledgments}

We thank Claude Murat for his helpful advice on OTUs assignation. We thank Leila Djied for assistance with root molec- ular analyses, Rémi Lacercat and Christian Mustin for their support in microscopy and imaging processing. Laurence Lacercat-Didier received a PhD grant from ADEME (Agence de l'Environnement et de la Maitrise de l'Energie) and the Lorraine region. Elena Martino was supported by the World Wide Style project of the University of Turin. This work was supported by ADEME (PROLIPHYT 1172C0053) and by the Agence Nationale de la Recherche (ANR) under the PRECODD (ANR-06- ECOT-015-01-PHYTOPOP) and the Blanc International (ANR10- INTB-1703-01-BIOFILTREE) programs.

\section{References}

Adriaensen K, Vrålstad T, Noben J, Vangronsveld J, Colpaert JV (2005) Copper-adapted Suillus luteus, a symbiotic solution for pines colo- nizing Cu mine spoils. Appl Environ Microbiol 71:7279-7284. doi: 10.1128/AEM.71.11.7279

Altschul SF, Madden TL, Schaffer AA, Zhang J, Zhang Z, Miller W, Lipmann DJ (1997) Gapped BLAST and PSI-BLAST: a new gen- eration of protein database search programs. Nucleic Acids Res 25: 3389-3402

Ban Y, Tang M, Chen H, Xu Z, Zhang H, Yang Y (2012) The response of dark septate endophytes (DSE) to heavy metals in pure culture. PLoS One 7:e47968. doi:10.1371/journal.pone.0047968

Bellion M, Courbot M, Jacob C, Blaudez D, Chalot M (2006) Extracellular and cellular mechanisms sustaining metal tolerance in ectomycorrhizal fungi. FEMS Microbiol Lett 254:173-181. doi: 10.1111/j.1574-6968.2005.00044.x

Benjdia M, Rikirsch E, Müller T, Morel M, Corratgé C, Zimmermann S, Chalot M, Frommer WB, Wipf D (2006) Peptide uptake in the ectomycorrhizal fungus Hebeloma cylindrosporum: characterization of two di- and tripeptide transporters (HcPTR2A and B). New Phytol 170:401-410. doi:10.1111/j.1469-8137.2006.01672.x

Blaudez D, Jacob C, Turnau K, Colpaert JV, Finlay R, Botton B, Chalot M (2000) Differential responses of ectomycorrhizal fungi to heavy metals in vitro. Mycol Res 104:1366-1371

Bonito G, Reynolds H, Robeson MS, Nelson J, Hodkinson BP, Tuskan G, Schadt CW, Vilgalys R (2014) Plant host and soil origin influence fungal and bacterial assemblages in the roots of woody plants. Mol Ecol 23:3356-3370. doi:10.1111/mec.12821

Boyle H, Zimdars B, Renker C, Buscot F (2006) A molecular phylogeny of Hebeloma species from Europe. Mycol Res 110:369-380. doi:10. 1016/j.mycres.2005.11.015

Brundrett M, Bougher N, Dell B, Grove T, Malajczuk N (1996) Working with mycorrhizas in forestry and agriculture. ACIAR Monograph 32, Canberra 
Capuana M (2011) Heavy metals and woody plants—biotechnologies for phytoremediation. iForest - Biogeosciences and Forestry 4:715. doi:10.3832/ifor0555-004

Colpaert JV, Vandenkoornhuyse P, Adriaensen K, Vangronsveld J (2000) Genetic variation and heavy metal tolerance in the ectomycorrhizal basidiomycete Suillus luteus. New Phytol 147:367-379. doi:10. 1046/j.1469-8137.2000.00694.x

Colpaert JV, Muller LAH, Lambaerts M, Adriaensen K, Vangronsveld J (2004) Evolutionary adaptation to Zn toxicity in populations of Suilloid fungi. New Phytol 162:549-559. doi:10.1111/j.1469- 8137.2004.01037.x

Colpaert JV, Wevers JHL, Krznaric E, Adriaensen K (2011) How metal- tolerant ecotypes of ectomycorrhizal fungi protect plants from heavy metal pollution. Ann For Sci 68:17-24. doi:10.1007/s13595-010- 0003-9

Danielsen L, Lohaus G, Sirrenberg A, Karlovsky P, Bastien C, Pilate G, Polle A (2013) Ectomycorrhizal colonization and diversity in relation to tree biomass and nutrition in a plantation of transgenic pop- lars with modified lignin biosynthesis. PLoS 0ne 8:e59207. doi:10. 1371/journal.pone.0059207

Fomina MA, Alexander IJ, Colpaert JV, Gadd GM (2005) Solubilization of toxic metal minerals and metal tolerance of mycorrhizal fungi. Soil Biol Biochem 37:851-866. doi:10.1016/j.soilbio.2004.10.013

Gehring CA, Mueller RC, Whitham TG (2006) Environmental and ge- netic effects on the formation of ectomycorrhizal and arbuscular mycorrhizal associations in cottonwoods. Oecologia 149:158-164. doi:10.1007/s00442-006-0437-9

Gonçalves SC, Martins-Loução MA, Freitas H (2009) Evidence of adap- tive tolerance to nickel in isolates of Cenococcum geophilum from serpentine soils. Mycorrhiza 19:221-230. doi:10.1007/s00572-008- 0211-4

Hamzeh M, Dayanandan S (2004) Phylogeny of Populus (Salicaceae) based on nucleotide sequences of chloroplast trnT-trnF region and nuclear rDNA. Am J Bot 91:1398-1408

Hrynkiewicz K, Baum C, Leinweber P, Weih M, Dimitriou I (2010) The significance of rotation periods for mycorrhiza formation in Short Rotation Coppice. For Ecol Manag 260:1943-1949. doi:10.1016/j. foreco.2010.08.020

Jourand P, Ducousso M, Loulergue-Majorel C, Hannibal L, Santoni S, Prin Y, Lebrun M (2010) Ultramafic soils from New Caledonia structure Pisolithus albus in ecotype. FEMS Microbiol Ecol 72: 238-249. doi:10.1111/j.1574-6941.2010.00843.x

Karliński L, Rudawska M, Kieliszewska-Rokicka B, Leski T (2010) Relationship between genotype and soil environment during colonization of poplar roots by mycorrhizal and endophytic fungi. Mycorrhiza 20:315-324. doi:10.1007/s00572-009-0284-8

Karliński L, Rudawska M, Leski T (2013) The influence of host genotype and soil conditions on ectomycorrhizal community of poplar clones. Eur J Soil Biol 58:51-58. doi:10.1016/j.ejsobi.2013.05.007

Khasa DP, Chakravarty P, Robertson A, Thomas BR, Dancik BP (2002) The mycorrhizal status of selected poplar clones introduced in Alberta. Biomass Bioenerg 22:99-104. doi:10.1016/S0961-9534(01)00072-1

Krpata D, Peintner U, Langer I, Fitz WJ, Schweiger P (2008) Ectomycorrhizal communities associated with Populus tremula growing on a heavy metal contaminated site. Mycol Res 112: 1069-1079. doi:10.1016/j.mycres.2008.02.004

Lamy I, Van Oort F, Dère C, Baize D (2006) Use of major- and trace- element correlations to assess metal migration in sandy Luvisols irrigated with wastewater. Eur J Soil Sci 57:731-740. doi:10.1111/j.1365-2389.2005.00765.x

Legrand L, Tap J, Gauthey C, Doré J, Caron C, Leclerc M (2008) RapidOTU: A fast pipeline to analyse 16S rDNA sequences by alignment of tetranucleotide frequency. In: Gut Microbiome Symposium 2008, 6th congress INRA Rowett Research Institut. Clermont-Ferrand

Likar M (2011) Dark septate endophytes and mycorrhizal fungi of trees affected by pollution. In:Pirttilä Jc, Franck C (ed) Endophytes of forest trees: biology and applications vol 80, pp 189-201

Likar M, Regvar M (2009) Application of temporal temperature gradient gel electrophoresis for characterisation of fungal endophyte communities of Salix caprea L. in a heavy metal polluted soil. Sci

Total Environ 407:6179-6187. doi:10.1016/j.scitotenv.2009.08.045 Likar M, Regvar M (2013) Isolates of dark septate endophytes reduce metal uptake and improve physiology of Salix caprea L. Plant Soil 370:593-604. doi:10.1007/s11104-013-1656-6 Meier S, Borie F, Bolan N, Cornejo P (2012) Phytoremediation of metal-polluted soils by arbuscular mycorrhizal fungi. Crit Rev Env Sci Tec $42 \cdot 741-775$

Migeon A, Richaud P, Guinet F, Chalot M, Blaudez D (2009) Metal accumulation by woody species on contaminated sites in the North of France. Water Air Soil Poll 204:89-101. doi:10.1007/s11270- 009-0029-5

Migeon A, Richaud P, Guinet F, Blaudez D, Chalot M (2012) Hydroponic screening of poplar for trace element tolerance and accumulation. Int J Phytoremediat 14:350-361. doi:10.1080/15226514.2011.620651

Murashige T, Skoog F (1962) A revised medium for rapid growth and bio assays with tobacco tissue cultures. Physiol Plantarum 15:473-497 Oberwinkler F, Riess K, Bauer R, Selosse M-A, Weiß M, Garnica S, Zuccaro A (2013) Enigmatic Sebacinales. Mycol Prog 12:1-27. doi:10.1007/s11557-012-0880-4 Pachlewski R, Pachlewska J (1974) Studies on symbiotic properties of mycorrhizal fungi of pine (Pinus sylvestris L.) with the aid of the method of mycorrhizal synthesis in pure cultures on agar. University of Warsaw

Ray P, Tiwari R, Reddy GU, Adholeya A (2005) Detecting the heavy metal tolerance level in ectomycorrhizal fungi in vitro. World J Microbiol Biotechnol 21:309-315. doi:10.1007/s11274-004-3572-7

Redon P-0, Béguiristain T, Leyval C (2009) Differential effects of AM fungal isolates on Medicago truncatula growth and metal uptake in a multimetallic (Cd, Zn, Pb) contaminated agricultural soil. Mycorrhiza 19:187-195. doi:10.1007/s00572-009-0230-9

Regvar M, Likar M, Piltaver A, Kugonič N, Smith JE (2010) Fungal community structure under goat willows (Salix caprea L.) growing at metal polluted site: the potential of screening in a model phytostabilisation study. Plant Soil 330:345-356. doi:10.1007/ s11104009-0207-7

Riess K, Oberwinkler F, Bauer R, Garnica S (2014) Communities of endophytic sebacinales associated with roots of herbaceous plants in agricultural and grassland ecosystems are dominated by Serendipita herbamans sp. nov. PLoS One 9:e94676. doi:10.1371/ journal.pone.0094676

Rodriguez RJ, White JF, Arnold AE, Redman RS (2009) Fungal endo- phytes: diversity and functional roles. New Phytol 182:314-330. doi:10.1111/j.1469-8137.2009.02773.x

Schneider CA, Rasband WS, Eliceiri KW (2012) NIH Image to ImageJ: 25 years of image analysis. Nat Methods 9:671-675. doi:10.1038/ nmeth. 2089

Selosse M-A, Dubois M-P, Alvarez N (2009) Do Sebacinales commonly associate with plant roots as endophytes? Mycol Res 113:10621069. doi:10.1016/j.mycres.2009.07.004

Shahabivand S, Maivan HZ, Goltapeh EM, Sharifi M, Aliloo AA (2012) The effects of root endophyte and arbuscular mycorrhizal fungi on growth and cadmium accumulation in wheat under cadmium toxicity. Plant Physiol Biochem 60:53-58. doi:10.1016/j.plaphy.2012.07.018

Singh LP, Gill SS, Tuteja N (2011) Unraveling the role of fungal symbi- onts in plant abiotic stress tolerance. Plant Signal Behav 6:175191 
Smith SE, Read DJ (2008) Mycorrhizal symbiosis. Academic, London Stefani FOP, Moncalvo J-M, Séguin A, Bérubé JA, Hamelin RC (2009) Impact of an 8-year-old transgenic poplar plantation on the ectomycorrhizal fungal community. Appl Environ Microbiol 75: 75277536. doi:10.1128/AEM.01120-09

Tamura K, Stecher G, Peterson D, Filipski A, Kumar S (2013) MEGA6: molecular evolutionary genetics analysis version 6.0. Mol Biol

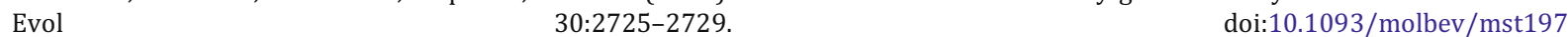
Trouvelot A, Kough JL, Gianinazzi-Pearson V (1986) Mesure du taux de mycorhization VA d'un système radiculaire. Recherches et méthodes d'estimation ayant une signification fonctionnelle. In: Gianinazzi S, Gianinazzi-Pearson V (eds) Mycorhizes : physiologie et génétique. INRA, Dijon, pp 217-220

Turnau K, Ryszka P, Gianinazzi-Pearson V, Van Tuinen D (2001) Identification of arbuscular mycorrhizal fungi in soils and roots of plants colonizing zinc wastes in southern Poland. Mycorrhiza 10: 169-174. doi:10.1007/s005720000073

Tuskan GA, Difazio S, Jansson S, Bohlmann J, Grigoriev I, Hellsten U, Putnam N, Ralph S, Rombauts S, Salamov A et al (2006) The genome of black cottonwood, Populus trichocarpa (Torr. \& Gray). Science 313:1596-1604. doi:10.1126/science.1128691

Vallino M, Massa N, Lumini E, Bianciotto V, Berta G, Bonfante P (2006) Assessment of arbuscular mycorrhizal fungal diversity in roots of Solidago gigantea growing in a polluted soil in Northern Italy. Environ Microbiol 8:971-983. doi:10.1111/j.1462-2920.2006.00980.x Wang Z, Binder M, Schoch CL, Johnston PR, Spatafora JW, Hibbett DS (2006) Evolution of helotialean fungi (Leotiomycetes, Pezizomycotina): a nuclear rDNA phylogeny. Mol Phylogenet Evol 41:295-312. doi:10.1016/j.ympev.2006.05.031

White TJ, Bruns T, Lee S, Taylor J (1990) Amplification and direct sequencing of fungal ribosomal RNA genes for phylogenetics. In: PCR protocols: a guide to methods and applications. Academic, New York, pp 315-322

Zarei M, König S, Hempel S, Khayam-Nekouei M, Savaghebi G, Buscot F (2008) Community structure of arbuscular mycorrhizal fungi as- sociated to Veronica rechingeri at the Anguran zinc and lead mining region. Environ Pollut 156:1277-1283. doi:10.1016/j.envpol.2008. 03.006 